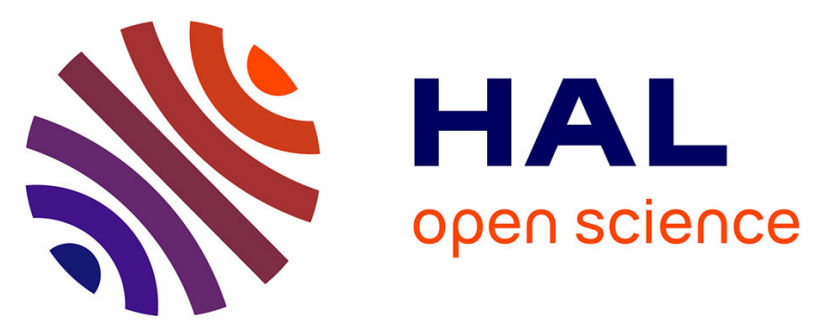

\title{
An investigation of the potential of interactive simulations for developing system thinking skills in elementary school: a case study with fifth- and sixth- graders
}

Maria Evagorou, Kostas Korfiatis, Christiana Nicolaou, Costas Constantinou

\section{To cite this version:}

Maria Evagorou, Kostas Korfiatis, Christiana Nicolaou, Costas Constantinou. An investigation of the potential of interactive simulations for developing system thinking skills in elementary school: a case study with fifth- and sixth- graders. International Journal of Science Education, 2009,31 (05), pp.655-674. 10.1080/09500690701749313 . hal-00516224

\section{HAL Id: hal-00516224 \\ https://hal.science/hal-00516224}

Submitted on 9 Sep 2010

HAL is a multi-disciplinary open access archive for the deposit and dissemination of scientific research documents, whether they are published or not. The documents may come from teaching and research institutions in France or abroad, or from public or private research centers.
L'archive ouverte pluridisciplinaire HAL, est destinée au dépôt et à la diffusion de documents scientifiques de niveau recherche, publiés ou non, émanant des établissements d'enseignement et de recherche français ou étrangers, des laboratoires publics ou privés. 


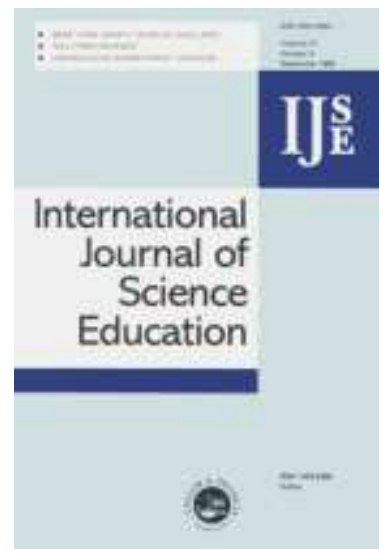

An investigation of the potential of interactive simulations for developing system thinking skills in elementary school: a case study with fifth- and sixth- graders

\begin{tabular}{|r|l|}
\hline Journal: & International Journal of Science Education \\
\hline Manuscript ID: & TSED-2007-0115.R2 \\
\hline Manuscript Type: & Research Paper \\
\hline Keywords: & $\begin{array}{l}\text { elementary school, inquiry-based teaching, information technology, } \\
\text { ecology education }\end{array}$ \\
\hline Keywords (user): & system thinking \\
\hline \multicolumn{2}{|l}{} \\
\hline
\end{tabular}

\section{S ScholaroNE \\ Manuscript Central}


Running head: SYSTEM THINKING SKILLS

\title{
An investigation of the potential of interactive simulations for developing system thinking skills in elementary school: a case study with fifth- and sixth- graders
}

\begin{abstract}
The purpose of this study was to investigate the impact of a simulation-based learning environment on elementary school students' (11- to 12- year old) development of system thinking skills. The learning environment included interactive simulations using the Stagecast Creator software to simulate the ecosystem of a marsh. Simulations are an important tool in any effort to develop system thinking, because they have the potential to highlight the dynamic nature of systems. Before the implementation of the learning environment (over a period of 5 , 90 minutes lessons) two written tests were administered to the students, investigating the development of seven aspects of system thinking. The same tests were administered after the implementation. Specifically, four of the tasks included in each test were associated with skills concerning the structure and the elements of a system and three were associated with the processes and interactions taking place within a system. The findings indicated that elementary school students have the potential to develop system-thinking skills. The proposed learning environment provoked considerable improvements in some system thinking skills during a relatively brief learning process. However, the learning environment was not successful in promoting feedback thinking. We interpret these results in view of the difficulties encountered by the students. We also discuss the implications of our findings for the design of learning environments.
\end{abstract}




\title{
Introduction
}

System thinking, i.e. the ability to understand and interpret complex systems, is receiving increasing attention not only in education but also in everyday life (Essex Report, 2002; Jacobson \& Wilensky, 2006; Maani \& Maharai, 2004; Penner, 2000; Richmond, 2001; Wilensky \& Reisman, 2006). As Hogan (2000) puts it, system thinking is an important skill for navigating information highways, making decisions and solving problems in all aspects of personal, social and professional life. Appropriate choices and behaviours require an understanding of many complex relationships, and research suggests that system thinking skills are particularly important for facilitating and encouraging them. The importance of teaching system thinking skills within the context of science education lies in the fact that many phenomena around us (e.g. ecosystems, moon phase formation, energy transfer) are examples of complex systems, and an understanding of their function requires systemic thinking. Additionally, empirical studies suggest a link between the development of system thinking and conceptual understanding in science education (Grotzer \& Bell-Basca, 2003). Hence, researchers and educators highlight the importance of elaborating system thinking skills in the learning routine of specific scientific fields such as ecology, physics and social sciences as a prerequisite for conceptual understanding of the topics taught (Hogan \& Thomas, 2001; Klopfer \& Resnick, 2003; Stieff \& Wilensky, 2003; Wilensky \& Reisman, 2006). However, at the same time it is pinpointed that that there are relatively few studies regarding how students can learn complex systems, and that complex systems teaching is largely absent from compulsory education (Jacobson \& Wilensky, 2006)

\begin{abstract}
According to Assaraf and Orion (2005) 'a system is an entity that maintains its existence and functions as a whole through the interaction of its parts. However, this group of interacting, interrelated or interdependent parts that form a complex and unified whole must have a specific
\end{abstract}


purpose, and in order for the system to optimally carry out its purpose all parts must be present. Thus, the system attempts to maintain its stability through feedback. The interrelationships among the variables are connected by a cause and effect feedback loop, and consequently the status of one or more variables, affects the status of the other variables. Yet, the properties attributable to the system as a whole are not those of the individual components that make up the system' (Assaraf \& Orion 2005, p.519-520)

Accordingly, systemic thinkers - people who have developed the ability to think about systems - should be able to analyze interrelationships between different objects and explore emergent properties; analyze phenomena and problems in wider contexts; consider multiple cause-andeffect relationships; discover and represent dynamic processes (delays, feedback loops, oscillations) that underlie patterns of the system's behaviour; anticipate the long-term consequences and possible effects of present actions and understand changes in a system over time (Booth Sweeny et al. 2000; Kim, 1999; Maani \& Maharaj, 2004; Ossimitz 2000; Richmond, 2001; 2006).

Other researchers classify system thinking skills into hierarchical levels according to the difficulty for acquiring each skill. Specifically, Assaraf and Orion (2005) classified system thinking skills into four hierarchical levels: (a) Level 1 includes the ability to identify the system's components and processes (b) Level 2 includes the ability to identify relationships between separate components and the ability to identify dynamic relationships between the system's components, (c) Level 3 includes the ability to understand the cyclic nature of systems, the ability to organize components and place them within a network of relationships and the ability to make generalizations and (d) Level 4 includes an understanding of the hidden components of the system and the system's evolution in time (prediction and retrospection). Researchers proposing hierarchical classification of skills draw implications for teaching 
interventions. Assaraf and Orion (2005), for instance, proposed that each group of skills should serve as the basis for the development of the next higher group of skills.

Hmelo, Holton and Kolodner (2000) and Hmelo-Silver and Pfeffer (2004) adopted the Structure - Behaviour - Function (SBF) framework for explaining complex systems and identifying system thinking skills. In this framework, 'Structure' refers to the physical structure of the system, 'Behaviour' refers to the dynamic mechanisms that allow the structures to carry out the system's function and 'Function' refers to the purpose of the system and subsystems. The researchers use the same framework to classify the necessary skills for grasping systems. According to their findings, skills for comprehending the structure and the visible aspects of the behaviour of a system are the most easily acquired by young students.

\section{System thinking and science education}

Even though system thinking is highly related both to the nature of science and nature itself, it is often neglected in the design of science learning environments (Golan \& Reiser, 2002). This is because most educational systems place emphasis on the canonical content of science rather than on skills and thinking that are related to the socio-humanistic perspectives of science (Aikenhead, 2006). Hannon and Ruth (2000) argued that in formal education the emphasis is evidently placed on events rather than processes over time, on parts rather than systems and on isolated processes rather than systemic relationships. Often in science education, our expectation is that students will be able to figure out for themselves the connections between parts, and understand interrelationships and effects. However, Hmelo-Silver and Azevedo (2006) argued that in order for students to think systemically, they need to be scaffolded for that.

Although some authors (Booth Sweeny, 2001) argue that children are natural system thinkers, since from the age of five months they experience and understand one-way causality (e.g. they 
cry to make their parents pick them up), there is consensus among empirical research that there are difficulties in developing advanced system thinking skills. People tend towards simple causal explanations of complex phenomena, missing the connectedness within systems and the complexity of processes (Jacobson, 2001; Wilensky \& Resnick, 1999). Often, they harbour deep-seated resistance towards ideas of a more systemic nature (Feltovich, Spiro \& Coulson, 1989; Resnick, 1994). According to Jacobson and Wilensky (2006), even university students tend to solve complex systems problems using simplistic arguments. Some of the earliest studies with younger students, conducted by Resnick (1996), showed that young students can potentially learn about complex systems and develop their system thinking but their knowledge is fragile and can easily revert to more simplistic ways of thinking. Results from a more recent study (Assaraf \& Orion, 2005) with middle school students indicate that most of them encounter, before a specially designed instruction, difficulties in all aspects of system thinking, even in the very basic ones.

Even though system thinking involves higher order thinking skills (Frank, 2000), there is empirical evidence that potentially these can be developed through specially designed instructional approaches that are appropriate for the age level of the learners (Resnick 1996; Wilensky \& Resnick, 1999; Wilensky \& Reisman; 2006 ). The proposed approaches are inspired by constructivist ideas asserting that learners are actively constructing new understanding, rather than passively absorbing facts (Klopfer \& Resnick, 2003). Additionally, they adopt the prospect of inquiry as way of learning, according to which knowledge is fundamentally grounded on cycles of theorizing, model building and experimentation (Azevedo \& Hadwin, 2005; Kraicik et. al, 1998; Windschitl \& Thompson, 2006). Furthermore, Hmelo-Silver and Azevedo (2006) state that the use of computer-based learning environments can be the key to the development of an understanding of systems and their behaviour. By including assumptions in interactive simulations for instance, the students can test them, and 
explore the structure, behaviour and function of systems. Hogan and Thomas (2001) claim that simulations are an important tool for building system understanding and thinking, because they show the dynamic nature of systems: 'Describing and predicting how complex systems behave, necessitates going beyond static structural depictions of cause/effect relationships among variables to show the net effects of all these relationships interacting simultaneously' (Hogan \& Thomas, 2001, p.320). This was also supported by Kurtz dos Santos and Ogborn (1994) who argue that students learn more about system behaviour with dynamic computer models rather than when they create static depictions of system relationships. They also make the claim that with interactive virtual environments students engage in an authentic scientific practise of using models as tools of observation, exploration, synthesis and prediction, thereby learning about the nature of science. Wilensky and Resnick (1996) which used the modelling tool StarLogo share the same positive opinion about the effect of computer-based tools in improving system thinking skills.

\section{Purpose of the study}

The purpose of this study was to investigate the impact of a simulation-based learning environment on elementary school students' development of system thinking skills. Seven thinking skills were investigated, which we consider that cover the full range of system thinking skills, as they appear in the bibliography (Assaraf \& Orion, 2005; Essex Report, 2002; Hmelo-Silver \& Pfeffer, 2004; Sheehy, Wylie, McGuinness \& Orchard, 2000). Specifically, four of the skills concerned the elements of the structure of a system and three were associated with the processes and interactions taking place within a system's structure. Skills concerning the structure of a system included (i) identification of the elements of a system, (ii) identification of the spatial boundaries of a system (iii) identification of temporal boundaries of a system, and (iv) students' ability to conceive the existence of several sub-systems within a 
Our research draws from the fact that there are limited resources for teaching systemic thinking within science, especially for younger students, and involved the designing of a learning environment with the potential to support elementary school students in their effort to develop their system thinking skills. A number of studies have investigated pre-college and college students' systemic thinking skills in specific domains and proposed ways to improve them through learning interventions (Golan \& Reiser, 2004; Ossimitz, 2000; Richmond, 1994). However elementary school students' system thinking is still largely unexplored. Even though empirical evidence suggests that young students can to a certain extend develop their systemic thinking, only few examples of interventions that target elementary school students can be found in the literature (Hmelo,, Holton \& Kolodner, 2000; Resnick \& Wilensky, 1993; Wilensky \& Resnick, 1999). A possible explanation for that is that evidence provided by research on young students' ability to develop system thinking skills are not conclusive and researchers continue to dispute on the importance to teach system thinking skills in the elementary school (Hmelo-Silver \& Azevedo, 2006).

\section{Methods}

Sample and context of the study

Thirteen, 11- to 12- year old students, nine boys and four girls, comprised the sample. The participants were students of a school in a suburban region of the capital of Cyprus, Nicosia, who voluntarily follow after school computer lessons, offered by the teachers of their school 
and two of the writers of the present paper. None of the students had previous experience with computers or inquiry-based learning environments. Before engaging with the learning environment, students were familiarized with a concept mapping software and the use of Internet search engines. Participants were of mixed ability and socioeconomic status. All participants were described by their teachers as being academically able, but not as being high achievers.

The learning intervention was implemented over a period of five sessions, by the first and third authors of the paper. Group meetings among the researchers prior to each lesson focused on the rationale of the activity sequence, the possible difficulties that students might encounter during instruction and the ways to overcome them. The researchers met with the students twice a week for 90- minute periods.

\section{The learning environment: OIKOSKEPSI}

Practising of participants on system thinking skills was actually the first part of a wider educational project called OIKOSKEPSI. OIKOSKEPSI in Greek means thinking about one's home, which in this case is the Earth. The learning environment introduced a controversial environmental issue associated with extensive annoyance in a village by the mosquitoes reproduced in a nearby marsh. OIKOSKEPSI was designed according to project-based learning (Krajcik et al., 1998), a guided discovery approach that asks students to work in groups and search for information in order to address a question. Principles of inquiry through modelling were also applied. More specifically, OIKOSKEPSI is in line with constructivism, according to which knowledge is constructed in a person's mind, and it is based on a person's experience with the world, and proposes that humans construct new knowledge when building new artifacts, in this case, models (Von Glaserfeld 1995; Kafai \& Resnick, 1996). Models can 
potentially help students frame questions for specific investigations, which at the same time help the interpretation of inquiries (Windschitl \& Thompson, 2006).

In addition to the above general framework, the learning environment implemented the design principles for learning about complex systems, as were expressed in Jacobson and Wilensky, (2006), i.e: experiencing complex systems, making the system framework explicit, encouraging collaboration, discussion and reflection, constructing theories and models, facilitating deep understanding (see also Hmelo et al., 2000; National Research Council, 2000). Specifically, the Stagecast Creator software was used to create interactive simulations of a marsh ecosystem. It has been suggested that through in-depth interaction with simulations, students gain an understanding of the conceptual framework, the complexity and the systemic structure of ecosystems (Hestenes, 1992; Stratford, Krajcik \& Soloway, 1998; Wilensky \& Reisman, 2006). In the case of OIKOSKEPSI, simulations were used to allow students to virtually explore the system of the marsh and to investigate the effects of various changes. In that way, the students did not have to struggle with imagining the implications of their suggestions; the simulations made it easier to visualize changes and hence to think more effectively through the effects of the actions they proposed, and also to explore more possibilities.

During the first lesson, students were given access to the computer simulation of a marsh ecosystem and they worked in pairs in order to identify the elements of the marsh and record them on a specially designed worksheet. Figure 1 below shows an instant from the computer simulation, and two of the questions that accompanied the specific instant of the simulation. The questions were designed using prompts to scaffold students to give more specific responses. Each pair was asked to discuss their findings with other classmates in a process facilitated by the researchers. Students also used the same simulation to study simple processes 
of the marsh, such as the seasonal variation of the population of certain species, or the fluctuations in the water level of the marsh.

\section{[INSTERT FIGURE 1 HERE]}

During the second and third sessions, pairs of students engaged in discussions about the marsh as a system that consists of subsystems and has identifiable interactions between its elements. Specifically, students were asked to identify in the simulation the habitat of a certain species, such as the mosquitoes or the herons. They were also asked to identify predator-prey relationships and to study the relationship between water level fluctuations and changes in the size of the mosquito population. We provided additional interactive simulations, which helped students work through these activities. For instance, the simulations helped the students to 'observe' the area that a species is moving around (and thus to use it as a clue of its habitat), or to 'observe' what happens when the level of water in the marsh rises.

During the last two sessions, students continued to work in pairs using all the simulations in order to understand the marsh as a system through specific activities. They tried various solutions for the control of mosquitoes (e.g. remove the water from the swamp, spray with different chemicals, introduce new species: eucalyptus, mosquito fish) and were able to see the effects of each one of the solutions on the ecosystem or on individual elements of it over a period of time. For instance, in the simulation shown in Figure 2 students could introduce a new species - specifically the eucalyptus - in the marsh. The students could observe various changes occurring to the system while the simulation was running.

[INSERT FIGURE 2 HERE] 


\section{Data collection}

Two tests were administered to the students before and after instruction (Table 1). The context of the first test was associated with the managing system of a pizzeria ('Pizzeria Test'). A scenario was presented to the students according to which two sisters are managing a pizzeria in a town called Pizza city. Details about the clients and employees in the pizzeria were presented. A map of the city, with the pizzeria and the location of the clients was also provided. The second test was associated with the ecosystem of a forest ('Forest Test'). A picture in the test presented a forest with a lake and various animals.

Each test consisted of seven tasks corresponding to the seven thinking skills under investigation. Specifically, tasks $1-4$ were associated with skills concerning the elements of the structure of a system and tasks $5-7$ were associated with the processes and interactions taking place within a system's structure (Table 1).

\section{[INSERT TABLE 1 HERE]}

The two tests were designed so as to probe the extent to which students could apply their system thinking skills in new unfamiliar contexts. Specifically, the 'forest test' referred to an environmental system that was closely related to the one presented in the learning environment (near-transfer), while the 'pizzeria test' presented a totally different type of system (far- 
transfer).

\section{Data Analysis}

Students' responses to tasks were content analysed by two of the authors and classified in categories. Inter-coder reliability amounted to 95\%. Incosistencies were resolved through discussion between the authors. More specifically, concerning responses to Task 1, we analytically recorded the elements of the system mentioned by the students for both tests, as they are presented in the first columns of Tables 2 and 3. For the remaining tasks, responses were classified in categories representing levels of precision and completeness of answers: Level 1 represented complete failure of the student to deal with the task, Level 2 included partially successful responses to the task, and in Level 3 included the scientifically accepted responses. The criteria for content analysing and classifying responses were specific for each task, and they are presented in the first column of Table 4.

Similar approaches of content analysing, coding and classifying responses to tasks within an environmental context, are considered common in ecological education literature (Grotzer \& Bell Basca, 2003; Hogan, 2000; Korfiatis et al., 2004)

\footnotetext{
Results

Skill 1: Identification of the elements of a system

Tables 2 and 3 summarize how the students responded to pre and post-tests about different aspects of a system. In the forest test (Table 2), students mentioned a large number of ecosystem elements (such as plants, animals and water) already before the instruction. However, after the instruction the total number of referred elements increased, as well as the number of elements referred by each child (as in the case of 'snakes', 'monkeys', 'eagles', 'crows', and 'flowers').
} 


\title{
[INSERT TABLE 2]
}

In the pizzeria test (Table 3), more students included in their post-test the employees and the material objects needed for a pizzeria to operate, while, in the pre-test, many students restricted the elements of a pizzeria to the stuff needed for the construction of a pizza, and three students provided no answer. A girl for example who mentioned only the ingredients of a pizza in the pre-test, in the post-test said that 'the business of the pizzeria included a building with a label outside saying 'pizzeria', people who make the pizza and cheese and bread for the pizza'. Another student answered in the post-test that 'the pizzeria includes the motorcycle for the delivery, pastry for the pizza, tables and chairs for the clients'.

\section{[INSERT TABLE 3]}

\section{Skills 2 and 3: Recognition of the temporal and spatial boundaries of a system}

As far as students' ability to recognize spatial and time boundaries is concerned (Skills 2 and 3), there is evidence of improvement in both tasks, even though in the spatial boundaries task there was already a good percentage of correct answers present in the pre-test (Table 4).

\section{[INSERT TABLE 4]}

\begin{abstract}
More specifically, in the case of spatial boundaries, the task in the 'forest test' asked students to identify the boundaries of a sub-system of the forest which corresponds to what in ecological terms would be called the 'niche' of the frog, i.e. an area of the forest which should include the place of nesting of the frog, as well as the species that frogs are feeding with. In the pre-test,
\end{abstract}


four students chose to select only the lake as their answer, without including any biotic element of frogs' niche. In the post-test, twelve out of thirteen students chose to include frogs together with substantial elements of their living, such as the vegetation near them, a part of the lake and insects. In a similar vein, in the relevant task from the pizzeria pre-test, three children initially considered as boundaries of the pizzeria only the building of the enterprise, while after instruction, twelve students included in the boundaries of the enterprise the part of the city where clients of the pizzeria actually inhabit. Overall, especially after instruction, it was apparent to the participating students that the boundaries of a system or a sub-system are extremely relevant with the relationships and processes among its elements. For example, one boy explained his response by writing, 'it has no meaning to include the other buildings because the delivery boy does not go there'.

Most students were not able to identify the temporal boundaries of a system in the pre-test (Skill 3). In the pizzeria post-test, 11 out of 13 students were able to identify reasonable time boundaries for each system providing an explanation for their answer. In the pizza pre-test, some students chose the second table because it provided more time specific data (it was restricted to only two rows, even though it referred to past periods and so it was not proper for the task students had to answer). After the instruction, most students were able to process the analytic table and to extract conclusions about a reasonable price for pizza.

On the other hand, this only holds true for four responses to the corresponding task in the 'forest' post-test. One of these four students stated that it 'is important to use all the data from 1960 onwards because the number of birds changes in small time periods, so you need to compare all the data'. On the contrary, many of the students kept their preference for the data from the most recent years, even though they were not sufficient for an appropriate decision. The increased complexity of the relevant task in the 'forest test' in comparison with the one in the 'pizzeria test' is probably an explanation for the difference in these results. 


\section{Skill 4: Conceive the existence of several sub-systems within a system}

Improvement was apparent in both tests when students were asked to locate the subsystems of a given system (Task 4 - Table 4). In the 'pizzeria test' eight students were not able to answer the question prior to instruction, five of them were able to identify isolated elements, and none of them was able to identify subsystems or provide an explanation. Students mentioned isolated objects such as the pizza itself. After the instruction, only two students failed to answer the question, four students were able to identify elements of a system and seven of them were able to identify subsystems and provide an explanation regarding these subsystems. After the intervention, three students provided as an example of a sub-system various ingredients used in the making of a pizza, explaining that the pizza we eat consists of those elements. Another student mentioned as a sub-system of the pizzeria, the delivery boy and the motorcycle used to deliver the pizza.

In the forest test, students were also asked to identify subsystems within the system, and indicate them in the picture provided. Prior to intervention eight students were not able to answer the question, five of them mentioned single elements and no subsystems, and none of them was able to identify subsystems and provide an explanation. After the instruction, only one student was not able to answer the question, three students were able to identify isolate elements of a system and nine of them were able to identify subsystems. For example, many students identified the lake with the fish and plants as one subsystem, and the water-plants and the frogs as another subsystem.

Skill 5: Identify the influence of specific elements of the system on other elements or the whole system 
Regarding the students' ability to identify relationships between systems elements and their influence on other elements or on the whole system, our study revealed the following (Task 5 Table 4): In the pizzeria test, students were asked to identify the influence caused on the system or its elements when one of the employees of the pizzeria could not be on duty due to illness. In the pre-test, one student was not able to provide an answer, five were able to identify an influence only to nearby elements (i.e. the other employee: for instance a boy stated that 'the other lady will get very tired'), four students stated that the system will not be affected since the other elements are still functioning (e.g.: 'there will not be a problem because the other lady will continue to make pizzas'), and only three of the students provided a more appropriate answer (such as: 'the work would not be done properly'). In the post-test, eleven students stated that there would be an influence to the behaviour of the system. A typical answer was the following: 'the work will be delayed and they will not be able to respond to the orders'. Interestingly, one student correlated the influence on the system with the conditions: 'If the pizzeria was busy, then the system would be influenced. If it was not very busy, the other employee could manage to run the business.' Similarly, in the 'forest post-test', eleven students gave the answer that the whole ecosystem will be destroyed. Four of them chose to give analytic answers by mentioning the order of disappearance of species (e.g.: 'monkeys and insects will die first because they feed on plants, then frogs because they feed on insects etc'). One student continues to insist after instruction that 'If the grass dies out then only the monkey will not have food and they will die or move to another forest'.

Skill 6: Identify the necessary changes that should take place in order to observe certain patterns

Concerning participating students' capacity to 'identify the necessary changes that need to take place in order to observe certain patterns', improvement was observed in the form of reduction 


\section{Skill 7: Identification of feedback effects in a system}

For Skill 7, students were asked to identify feedback effects within the 'pizzeria' and 'forest' systems. Students did not express cyclic reasoning, i.e. did not consider the fact that the influence of one element of the system on the others would eventually feed back to affect itself. In the pizza test for example, most students insisted, both before and after instruction to draw only linear connections between the elements constituting the system of a pizzeria business. They drew for e.g. a pizza in the middle and around it the ingredients of the pizza, or they made a linear connection between the shop, the pizza and the client. Only one student before instruction and two students after instruction drew a cyclic connection between the pizza, the employees of the pizzeria and the clients. Similar were the results of the 'forest test', where only one student answered after instruction that 'when monkeys decrease the grass will grow more because there will not be monkeys to eat it, so then monkeys would have a lot of food and they will start eating better, so the population will grow again'.

\section{Discussion}

i) The role of simulations in promoting elementary school students' system thinking skills 
System thinking skills are important in helping younger students understand many complex relationships that exist in the natural and social world (Maami \& Maharai, 2004). On the other hand, learning about complex systems is hard and, through many efforts reported in the literature, it has proven difficult to improve under current educational settings (National Research Council, 2000; Penner, 2000; Richmond, 2001; Sheehy et al., 2000). We also need to acknowledge that successful instructional designs prove to be time-consuming in their implementation (Hogan \& Thomas, 2001). The proposed approach, taking advantage of the prospects of interactive simulation, provoked improvements in the participants' system thinking skills, during a relatively time limited learning intervention. It should be noted that students' performance could be positively affected by the fact that they voluntarily participated in the project, and thus is very probable to share a positive attitude towards learning through computers. Indeed, it has been reported that there possibly exists an indirect correlation between attitudes towards the learning environment and student success (Brand et al., 2007). However, learning with interactive simulations has been proven to be effective also in averages samples (Azevedo, et al. 2004; Klopfer \& Resnick, 2003; Stieff \& Wilensky, 2003;). Future research could clarify this point.

Previous studies in system thinking mainly focused on secondary school and college students (Golan \& Reiser, 2004), ignoring elementary school students, and discussions regarding whether system thinking can be easily accessed by younger students still hold in the literature (Hmelo-Silver \& Azevedo, 2006). The findings of our study suggest that elementary school students can develop at least some system thinking skills when supported by a properly designed learning environment.

The learning environment was designed to take advantage of interactive computer simulations of a marsh. The simulation allowed students to have continuous access to the system under discussion, to explore the influence of various parameters on system structure and behaviour 


\section{ii) Accessing systemic thinking}

In our study we made use of two tests with parallel tasks relating to seven specified system thinking skills. The idea at the design stage was to test for near and far-transfer of knowledge learned during the course of an intervention on mosquitoes breeding in a marsh closed to an inhabited area. Hence we developed the tests in the context of a forest ecosystem (neartransfer) and a pizzeria business system (far-transfer). In practice the participants' performance was quite similar in both tests. This result is consistent with other studies proposing that complex systems share common principles, and demonstrating that people can transfer principles of system thinking across domains, at least when examined in the context of simulations (Goldstone \& Sakamoto, 2003).

As has already been noticed by other researchers, not all skills are equally easy to achieve (Hmelo-Silver \& Pfeffer, 2004). Our research has revealed that about half of the participating students had already attained in the pre-test a good level in three out of the seven skills we examined, namely those related with the identification of the elements and the spatial 
boundaries of a system, and the one concerning the identification of the factors causing certain patterns. The other four skills were initially quite undeveloped in the students of our sample. This finding is not in absolute agreement with those from other studies. Specifically, according to Hmelo et al. (2000), skills related to the structure of a system are developed by the students more easily. Nevertheless, system's understanding should not be restricted to a mere recognition of its elements: in pre-test students were capable of recognizing elements of a system (Task 1), but they could not identify subsystems (Task 4). Thus, even though subsystems are part of the structure of a system, they are more difficult to grasp than isolated elements, because they presuppose the comprehension of the relationships that connect the parts of a subsystem. In that aspect, our findings support the framework proposed by Assaraf and Orion (2005), according to which recognition of relationships is a higher order skill than recognition of elements.

Recognition of spatial and temporal boundaries is also an important skill, associated with the structure of a system and they are usually ignored in the research. The identification of time boundaries invokes difficulties for many children and it is an aspect of systemic thinking that will need more attention in future research. Our learning environment helped improve both spatial and temporal boundaries identification skills for most of the participants. It also improved the participants' skills in inferring the influence of a change on the system (Tasks 5 and 6), in contrast to many studies which considered those skills as difficult to achieve (Assaraf \& Orion, 2005). More specifically, the research literature reports that students encounter difficulties in their attempt to follow the effect of an action further than its neighbouring elements (White, 2000). It is also reported that students find it even more difficult to follow the opposite route, i.e. from the point of influence to the source of it (White, 2000). Such an understanding requires retrospective thinking, a skill that is considered difficult 


\section{Conclusion}

It is stated that research into learning about complex systems is still at an early stage (Jacobson \& Wilensky, 2006). Moreover, the issues related to the appropriateness of particular systems concepts for various age and development levels are among the ones needed further elaboration (Azevedo \& Hadwin, 2005). Thus, any clue on the "learnability" of complex system ideas by students, especially younger ones, is an important finding. Indeed, we consider that introduction of system thinking in elementary school is absolutely reasonable. The proposed learning approach, taking advantage of the possibilities of interactive simulations, provoked considerable improvements of system thinking skills, during a relatively time limited learning intervention. It also highlighted the effectiveness of inquiry-based environments, and of a 
curriculum on system thinking skills which allows for the gradual engagement of learners with systemic complexity, starting from the consideration of the elements of a system and concluding with the study of complex system's behavior. It is important to note the improvement, within the specific curriculum, of system thinking skills that are considered more sophisticated and difficult to achieve, such as the prediction of effects on distant elements of a system, or inferring the cause of a change from its consequences (Grotzer \& Bell Basca, 2003). Thus, findings of the present study question current hierarchical classification of system thinking skills, confirming that indeed learning sciences are at an early stage of understanding how students reason about complex systems (Hmelo-Silver \& Pfeffer, 2004). They also draw attention to the necessity of teaching specific system characteristics such as the spatial and temporal boundaries of a system, which are rather neglected in systemic research. It is to our concern that many studies report failure of elementary school students to grip with feedback thinking skills (Grotzer \& Bell Basca, 2003; White 2000; present study). Such findings point to the necessity for establishing of concise learning goals for each educational level. Future research could address similar questions on a larger scale aiming to enrich the emerging theoretical and empirical base for supporting students' learning about complex systems 


\section{Acknowledgements}

The research reported in this paper was supported by the Cyprus Research Promotion Foundation. The comments, suggestions and insights of Lucy Avraamidou and Justin Dillon on previous versions of this manuscript are gratefully acknowledged. 


\section{REFERENCES}

Aikenhead, G. S. (2006). Science Education for Everyday Life: Evidence-Based Practice. New York: Teachers College Press.

Assaraf, O., \& Orion, N. (2005). Development of system thinking skills in the context of earth science system education. Journal of Research in Science Teaching, 42(5), 518-560.

Azevedo, R., Winters, F. I., \& Moos, D. (2004). Can students collaboratively use hypermedia to learn science? The dynamics of self- and other-regulatory processes in an ecology classroom. Journal of Educational Computing Research, 31, 215-245.

Azevedo, R., \& Hadwin, A. F. (2005). Scaffolding self-regulated learning and metacognition implications for the design of computer-based scaffolds. Instructional Science, 33, 367379

Booth Sweeny, L. (2001). When a butterfly sneezes: A guide for helping kids explore interconnections in our world through favourite stories. USE: Pegasus.

Brand, S., Reimer, T., \& Opwis, K. (2007). How do we learn in a negative mood? Effects of a negative mood on transfer and learning. Learning and Instruction, 17, 1-16.

Essex Report (2002). The future of system dynamics and learner-centered learning in K-12 education. Presented at the International System Dynamics Society Conference 2002.

Frank, M. (2000). Engineering systems and systems thinking. Systems Engineering, 3, 63-168.

Feltovich, P. J., Spiro, R. J., \& Coulson, R. L. (1989). The nature of conceptual understanding in biomedicine: The deep structure of complex ideas and the development of misconceptions. In D. Evans \& V. Patel (Eds.), The cognitive sciences in medicine (pp. 113-172). Cambridge, MA: MIT.

Golan, R., \& Reiser, B. (2004). Investigating students' reasoning about the complexity manifested in molecular genetics phenomena. Paper presented at the Proceeding of American Educational Research Association, San Diego. 
Goldstone, R. L., \& Sakamoto, Y. (2003). The transfer of abstract principles governing complex systems. Cognitive Psychology, 46, 414-466.

Grotzer, T., \& Bell Basca, B. (2003). How does grasping the underlying causal structures of ecosystems impact students' understanding? Journal ofBiological Education, 38, 16-29.

Hannon, B., \& Ruth, M. (2000). Dynamic Modeling (2nd ed.). New York: Springer.

Hestenes, D. (1992). Modelling games in the Newtonian world. American Journal of Physics. $60(8), 732-748$.

Hmelo, C., Holton, D., \& Kolodner, J. (2000). Designing to Learn About Complex Systems. The Journal of the Learning Sciences, 9 (3), 247-298.

Hmelo-Silver, C. E. \& Pfeffer, M. G. (2004). Comparing expert and novice understanding of a complex system from the perspective of structures, behaviours, and functions. Cognitive Science, 28,127-138.

Hmelo-Silver, C. E. \& Azevedo, R. (2006). Understanding complex systems: some core challenges. The Journal of the Learning Sciences, 15 (1), 53-61.

Hogan, K. (2000). Assessing students' system reasoning in ecology. Journal of Biological Education, 35, 22-28.

Hogan, K., \& Thomas, D. (2001). Cognitive Comparison of Students' Systems Modelling in Ecology. Journal of Science Education and Technology, 10(4), 319-345.

Jacobson, M.J. (2001). Problem solving, cognition, and complex systems: differences between experts and novices. Complexity, 6(3), 4-49.

Jacobson, M., \& Wilensky, U. (2006). Complex Systems in Education: Scientific and Education Importance and Implications for the Learning Sciences. The Journal of the Learning Sciences, 15(1), 11-34.

Kafai, Y. B., \& Resnick, M. (1996). Constructionism in practice: Designing, thinking and learning in a digital world (1-8). New Jersey: Lawrence Erlbaum Associates. 
Kim, J. (1999). Making Sense of Emergence, Philosophical Studies, 96, 2-3, 3-36.

Klopfer, E. \& Resnick, M. (2003). Technologies to support the creation of complex systems models: Using Starlogo software with students. Biosystems, 71, 111-123.

Krajcik, J., Blumenfeld, P. C., Marx, R., Bass, K. M., Fredricks, J., \& Soloway, E. (1998). Inquiry in project-based science classrooms: Initial attempts by middle school students. Journal of the Learning Sciences, 3-4, 313-350.

Korfiatis, K., Stamou, A. G., \& Paraskevopoulos, S. (2004). Images of Nature in Greek primary school textbooks. Science Education, 88, 72-89.

Kurtz dos Santos, A.C. \& Ogborn, J. (1994). Sixth form students' ability to engage in computational modelling. Journal of Computer Assisted Learning, 10 (33), 182-199.

Maani,K., \& Maharaj, V. (2004). Links between systems thinking and complex decision making. Systems Dynamics Review, 20(1), 21-48.

National Research Council. (2000) How people learn: Brain, mind, experience and school. J. D. Bransford, A. L. Brown, R.R. Cocking \& S. Donovan (eds). Committee on developments in the science of learning and committee on learning research and educational practice. Washington DC: National Academy Press.

Ossimitz, G. (2000). Entwicklung systemischen Denkens. München: Profil Verlag.

Penner, D., (2000). Explaining systems: Investigating middle school students' understanding of emergent phenomenaRichmond, B. (2001). An Introduction to Systems Thinking, High Performance Systems, Inc. Lebanon, NH.

Richmond, B. (1994). System Dynamics/Systems Thinking: Let's Just Get On With It. Paper presented at the International Systems Dynamics Conference, Sterling, Scotland.

Resnick, M. (1994). Turtles, Termites and Traffic Jams: Explorations in Massively Parallel Microworlds. MIT Press, Cambridge, MA. 
Resnick, M. \& Wilensky, U. (1993). Beyond the deterministic, centralized mindsets: New thinking for new sciences. Proceedings of the Annual American Educational Research Association.

Resnick, M. (1996). Beyond the centralized mindset. Journal of the Learning Sciences, 5, $1-22$.

Sheehy, N. P., Wylie, J. W., McGuinness C., \& Orchard, G. (2000). How children solve environmental problems: Using computer simulations to investigate systems thinking. Environmental Education Research, 6, 109-126.

Stieff, M. \& Wilensky, U. (2003). Connected Chemistry: incorporating interactive simulations into the chemistry classroom. Journal of the Science Education and Technology, 12, 285-302.

Stratford, S. J., Krajcik, J., \& Soloway, E. (1998). Secondary students' dynamic modelling processes: Analyzing, reasoning about, synthesizing, and testing models of stream ecosystems. Journal of Science Education and Technology, 7, 215-234.

Von Glaserfeld, E. (1995). Radical constructivism: A way of knowing and learning. Washington, DC: The Falmer Press.

Windschitl, M., \& Thompson, J. (2006). Transcending simple forms of school science investigation: The impact of preservice instruction on teachers' understandings of modelbased inquiry. American Educational Research Journal, 43(4), 783-835.

Wilensky, U. \& Resnick, M. (1999). Thinking in levels: A dynamic systems perspective to making sense of the world. Journal of Science Education and Technology, 8 (1), 3-19.

Wilensky, U., \& Reisman, K., (2006). Thinking like a wolf, a sheep, or a firefly: Learning biology through constructing and testing computational theories - an embodied modelling approach. Cognition and Instruction, 24 (2), 171-209.

White, P. A. (2000). Naïve analysis of food web dynamics: a study of causal judgment about complex physical systems. Cognitive Science, 24 (4), 605-650. 
Figure 1: Screenshots from a Stagecast simulation representing the ecosystem of the marsh and two questions from the worksheet 


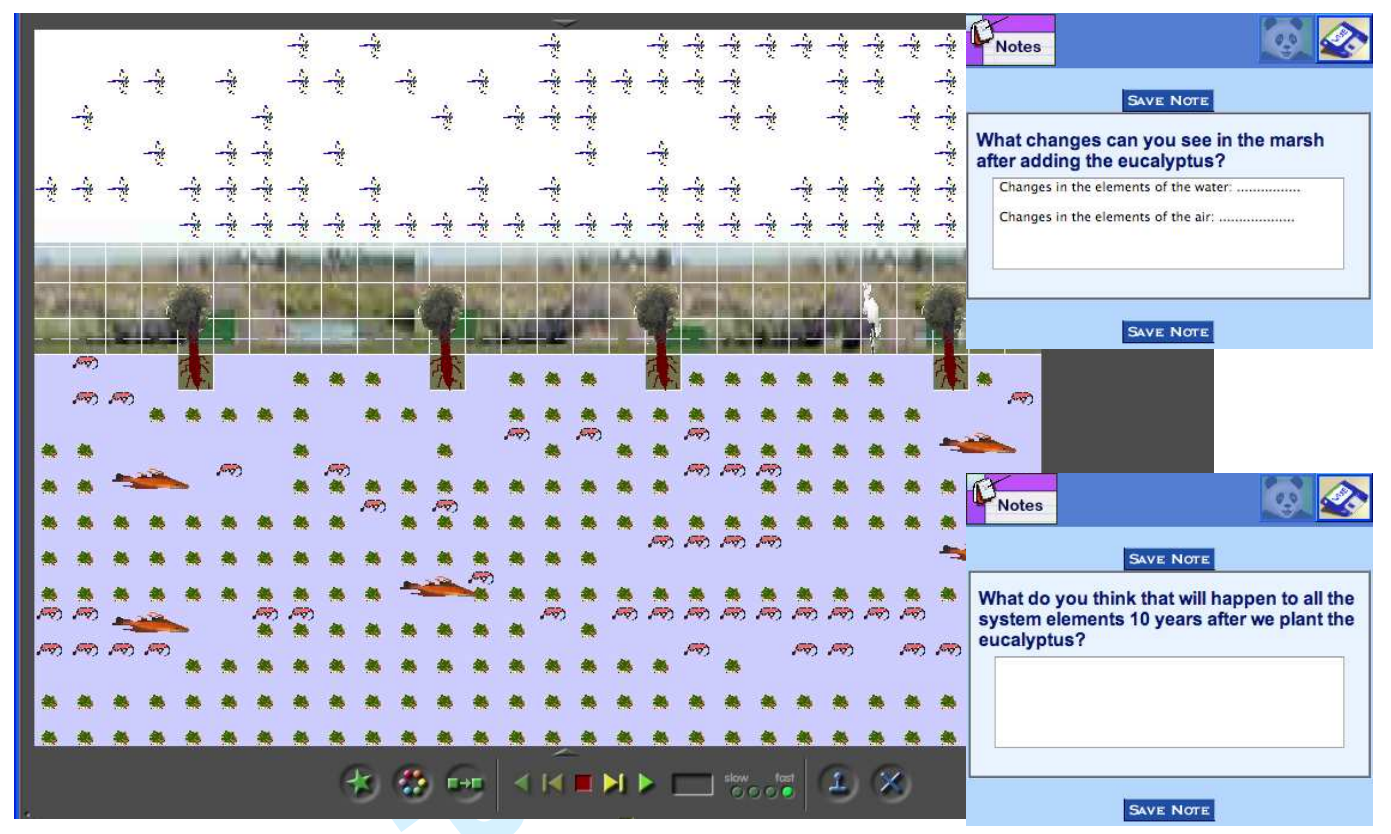

Figure 2: Screenshots from a Stagecast simulation showing a change in the ecosystem of the marsh and two questions from the worksheet 


\section{Evaluated skills}

Skill 1: Identification of the elements of a system.

Skill 2: Identification of the spatial boundaries of a system.

Skill 3: Identification of the temporal boundaries of a system.

Skill 4: Identification of several sub-systems within a single system.

Skill 5: Identification of the influence of specific elements of the system on other elements, or the whole system.

Skill 6: Identification of the changes that need to take place in order to observe certain patterns.
'Pizzeria test' tasks

'Forest test' tasks

Name the various elements that make up a pizzeria.

I would like to study the pizzeria as a system and how it operates.

On the map of the region around the pizzeria and its clients, draw the area that you think I should study

Two tables were provided to the students: A detailed table showing cheese and pizza prices for every year between 1994 and 2005; another table showing average cheese and pizza prices for each of the decades 1980-1990 and 1990-2000. The students were asked: Which table would you choose to use in order to decide if the price of the pizza is influenced by the price of cheese.

A system is a set of elements that interact with each other. The pizzeria is an example of a system. Can you name any other smaller sub-systems within the pizzeria system? The description and the picture might help you in answering this question.

One of the two sisters who run the pizzeria fell sick one day and could not go to work. How do you expect that this will influence the operation of the pizzeria?

The pizzeria needs to start selling more pizzas. What changes would need to take place in order for this to occur?
Name the various elements that make up a forest.

I would like to study the frogs and how they survive in the forest as a system. On the picture of the forest, indicate the area that you think I should study.

Two tables were provided to the students: one with bird population data between 1960 and 1975 showing a decreasing population; the other with population data between 1985 and 1995 showing an increasing population. They were asked to indicate which data they would need to use in order to study population changes over a 20 year period.

A system is a set of elements that interact with each other. The forest is an example of a system. Can you name any other smaller sub-systems within the forest system? The description and the picture might help you in answering this question.

One tree was infected by a bug and it died. Gradually other trees began to be affected as well. How do you expect that this will influence the rest of the forest?

The monkey population in the forest has suddenly decreased. What might have caused that change? 
Skill 7: Identification of feedback effects in a system.

Draw a concept map of all the connections between the different elements of the pizzeria system, in order to show how one affects the other. Please make sure that you will include the clients and the pizzeria in your drawings.
The monkey population decreased for some years. Then the number of monkeys in the forest began to increase again. How could this happen?

Table 1: Tasks included in assessment tests and the corresponding skills evaluated. 


\begin{tabular}{|c|c|c|}
\hline Elements & Before $(n=13)$ & After $(n=13)$ \\
\hline Animals & 11 & 11 \\
\hline Monkeys & 5 & 7 \\
\hline Snakes & 0 & 4 \\
\hline Birds & 4 & 4 \\
\hline Insects & 2 & 2 \\
\hline Frogs & 3 & 3 \\
\hline Crows & 8 & 3 \\
\hline Eagle & 0 & 3 \\
\hline Butterflies & 3 & 3 \\
\hline Flies & 3 & 3 \\
\hline Bugs & 1 & 1 \\
\hline Plants & 7 & 7 \\
\hline Trees & 12 & 10 \\
\hline Bushes & 1 & 2 \\
\hline Flowers & 1 & 2 \\
\hline Soil & 1 & 1 \\
\hline Rocks & 1 & 2 \\
\hline Water & 3 & 3 \\
\hline \multicolumn{3}{|c|}{ Table 2: Children's answers to the question 'name the } \\
\hline variou & nents that make & forest' \\
\hline
\end{tabular}




\begin{tabular}{ccc}
\hline Elements & Before (n=13) & After ( $\mathrm{n}=13)$ \\
\hline Pizza's ingredients (e.g. cheese, ham) & 9 & 9 \\
Employees (e.g. cook, delivery boy) & 3 & 7 \\
Objects (e.g. oven, telephone, & 5 & 0 \\
motorcycle) & 3 & \\
No answer & & \\
\hline Table 3: Children's answers to the question 'name the elements that make up a \\
$\quad$ pizzeria'
\end{tabular}




\begin{tabular}{cccccc}
\hline Skills & \multicolumn{2}{c}{ 'Pizza Test' } & \multicolumn{2}{c}{ 'Forest Test' } \\
& Pre & Post & Pre & Post \\
& $(n=13)$ & $(n=13)$ & $(n=13)$ & $(n=13)$ \\
\hline
\end{tabular}

Skill 2: Identification of the spatial boundaries of a system.

Level 1: No answer

Level 2: They choose individual elements as the system

Level 3: They choose as boundaries of the system the areas in

3

which they see elements of the system

8

$\begin{array}{ccc}0 & 2 & 0 \\ 1 & 4 & 1 \\ 12 & 7 & 12\end{array}$

Skill 3: Identification of the temporal boundaries of a system.

Level 1: No answer

Level 2: They do not confine the time boundaries to the time of the problem but they choose to study the most convenient data

Level 3: They confine the time boundaries to a reasonable time period

Skill 4 Identification of several sub-systems within a single system.

Level 1: No answer

Level 2: They identify elements of the system but not subsystems

Level 3: They describe subsystems

Skill 5: Identification of the influence of specific elements of the system on other elements, or the whole system.

\section{Level 1: No answer}

Level 2: They state that the system will not be affected since the other elements will continue functioning

Level 3: They state that only the closest elements will be affected

Level 4: They state that the behavior of the system will be affected

Skill 6: Identification of the changes that need to take place in order to observe certain patterns.

Level 1: No answer or irrelevant answer

Level 2: Change in only one of the parameters of the system Level 3: Changes in several parameters of the system
5

0

2

5

6

11

$0 \quad 4$

\section{8}

5

0

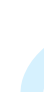


Skill 7 Identification of feedback effects in a system

Level 1: No answer $\quad \begin{array}{lllll}5 & 2 & 3 & 0\end{array}$

Level 2: Linear relationships between the elements of the $\begin{array}{lllll}7 & 9 & 10 & 12\end{array}$ system

Level 3: Description of feedback mechanisms

$2 \quad 0$

